\title{
Last Concentration
}

National Cancer Institute

\section{Source}

National Cancer Institute. Last Concentration. NCI Thesaurus. Code C85655.

The final measured concentration of a compound in a substance. In pharmacokinetics, it is the concentration corresponding to Tlast. 